\title{
Acute and constitutive increases in central serotonin levels reduce social play behaviour in peri-adolescent rats
}

\author{
Judith R. Homberg • Olga J. G. Schiepers • \\ Anton N. M. Schoffelmeer • Edwin Cuppen • \\ Louk J. M. J. Vanderschuren
}

Received: 21 March 2007 / Accepted: 9 July 2007 / Published online: 28 July 2007

(C) Springer-Verlag 2007

\begin{abstract}
Rationale Serotonin is an important modulator of social behaviour. Individual differences in serotonergic signalling are considered to be a marker of personality that is stable throughout lifetime. While a large body of evidence indicates that central serotonin levels are inversely related to aggression and sexual behaviour in adult rats, the relationship between serotonin and social behaviour during peri-adolescence has hardly been explored.

Objective To study the effect of acute and constitutive increases in serotonin neurotransmission on social behaviour in peri-adolescent rats.

Materials and methods Social behaviour in peri-adolesent rats (28-35 days old) was studied after genetic ablation of the serotonin transporter, causing constitutively increased extra-neuronal serotonin levels, and after acute treatment with the serotonin reuptake inhibitor fluoxetine or the serotonin releasing agent 3,4-methylenedioxymethamphetamine (MDMA). A distinction was made between social play behaviour that mainly occurs during peri-adolescence, and non-playful social interactions that are abundant during the entire lifespan of rats.
\end{abstract}

J. R. Homberg $(\bowtie) \cdot$ E. Cuppen

Hubrecht Institute, Uppsalalaan 8,

3584 CT Utrecht, The Netherlands

e-mail: j.homberg@niob.knaw.nl

L. J. M. J. Vanderschuren

Rudolf Magnus Institute of Neuroscience, Department of

Pharmacology and Anatomy, University Medical Center Utrecht,

Utrecht, The Netherlands

O. J. G. Schiepers $\cdot$ A. N. M. Schoffelmeer •

L. J. M. J. Vanderschuren

Department of Anatomy and Neurosciences, VU Medical Center,

Amsterdam, The Netherlands
Results In serotonin transporter knockout rats, social play behaviour was markedly reduced, while non-playful aspects of social interaction were unaffected. Acute treatment with fluoxetine or MDMA dose-dependently inhibited social play behaviour. MDMA also suppressed non-playful social interaction but at higher doses than those required to reduce social play. Fluoxetine did not affect non-playful social interaction. Conclusions These data show that both acute and constitutive increases in serotonergic neurotransmission reduce social play behaviour in peri-adolescent rats. Together with our previous findings of reduced aggressive and sexual behaviour in adult serotonin transporter knockout rats, these data support the notion that serotonin modulates social behaviour in a trait-like manner.

Keywords Serotonin · Social play · Peri-adolescence · Fluoxetine $\cdot$ Knockout rat $\cdot$ MDMA

There is a large body of literature that describes the association between serotonin (5-hydroxytryptamine, 5-HT) signalling, social status, aggression and sexual behaviour in humans and animals. For instance, cerebrospinal fluid (CSF) 5-hydroxyindoleacetic acid (5-HIAA; the major metabolite of 5-HT) levels are inversely related to aggression in humans, primates and rodents (Higley and Linnoila 1997; Fairbanks et al. 2001). Selective serotonin reuptake inhibitors (SSRIs), which are well-known anti-depressants, reduce impulsive aggression as well as sexual behaviour in humans (New et al. 2004; Olivier et al. 2006). Furthermore, depending on the social structure of the community, serotonergic drugs are able to interchange the dominant and subordinate status of community members (Edwards and Kravitz 1997; Larson and Summers 2001). It has been proposed that individual differences in 5-HT neurotransmission are an important 
neural underpinning of personality (Serretti et al. 2006), because central 5-HT levels are relatively stable throughout lifetime (Higley and Linnoila 1997). Studies showing that polymorphisms in 5-HT-related genes are linked to impulsive aggression in humans (Ferrari et al. 2005; Haberstick et al. 2006; Popova 2006) support the idea that the serotonergic modulation of social behaviour is heritable (Higley and Linnoila 1997).

An important form of social behaviour is social play behaviour, which is the earliest form of non-mother-directed social behaviour in young mammals. Social play behaviour consists of behaviours found in adult sexual, affiliative and aggressive encounters (Bolles and Woods 1964; Baenninger 1967; Poole and Fish 1975; Meaney and Stewart 1981). However, during social play, these behaviours are displayed in an exaggerated and/or out-of-context fashion (Poole and Fish 1975). In rats, a bout of social play behaviour starts with one rat soliciting another animal, by attempting to nose or rub the nape of its neck. If the animal that is solicited upon rotates to its dorsal surface, 'pinning' is the result, i.e. one animal lying with its dorsal surface on the floor with the other animal standing over it. From this position, the supine animal can initiate another bout of play, by trying to gain access to the other animal's neck. Thus, during social play, pinning, which is considered to be the most obvious posture in social play behaviour in rats, is not an endpoint but rather functions as a releaser of a prolonged play bout (Poole and Fish 1975; Pellis and Pellis 1987; Pellis 1988). The animal that is pounced upon can also respond by evading or by turning around to face the other animal. In the latter situation, a brief period of boxing/ wrestling may follow, in which the animals try to push each other away. If the solicited animal evades, the other animal may start to chase it, thus making another attempt to launch a play bout (see Vanderschuren et al. 1995a, for a detailed analysis of the temporal structure of social play behaviour in rats). It is thought that social play sub-serves the facilitation of social and cognitive development because play deprivation, i.e. social isolation during 2 weeks in periadolescence when social play is most abundant (i.e. from postnatal day 21 until postnatal day 35), leads to behavioural disturbances, most prominently in the social domain (e.g. Hol et al. 1999; Van den Berg et al. 1999). These behavioural changes are more selective than those of isolation rearing, which entails continuous isolation from weaning throughout further lifetime. This not only affects social behaviour (Ferdman et al. 2007) but also induces behavioural disturbances related to exploratory behaviour (Heidbreder et al. 2000), cognition (Heidbreder et al. 2000; Dalley et al. 2002; Bianchi et al. 2006) and reward sensitivity (Howes et al. 2000), suggesting that social play plays a rather selective role in the development of social skills.
There is evidence indicating that 5-HT modulates social play in non-human primates. For instance, low CSF 5-HIAA levels are associated with increased solitary play (Maestripieri et al. 2006; Higley and Linnoila 1997), although these findings are difficult to interpret in terms of central 5-HT levels. The neurobiology of social play has been widely investigated in rats (Vanderschuren et al. 1997; Siviy 1998), but surprisingly, little attention has been paid to the role of the serotonergic system in rat social play itself. While treatment with para-chloro-phenylalanine or a low tryptophan diet, resulting in a decrease in central 5-HT levels, did not affect social play, fenfluramine and the SSRI fluoxetine, agents that increase extra-neuronal 5-HT levels, inhibited play (Panksepp et al. 1987; Knutson et al. 1996). Further, the 5-HT receptor agonist quipazine reduced social play (Normansell and Panksepp 1985). These data suggest that there is an inverse relationship between 5-HT signalling and social play. Furthermore, the findings that 5-HT modulates social behaviour in peri-adolescent animals indicates that 5-HT affects social behaviour throughout development, consistent with the proposed trait-like relationship between 5-HT and social behaviour.

The serotonin transporter (SERT) critically regulates extracellular 5-HT levels by its re-uptake into pre-synaptic terminals (Lesch et al. 1996), and SERT knockout models would therefore be very useful to test the hypothesis that central 5-HT levels and social play behaviour are inversely related in a trait-like manner. SERT knockout mice are available (e.g. Bengel et al. 1998), which display reduced aggression (Holmes et al. 2002a) and social interaction (Kalueff et al. 2007). However, because social play behaviour in mice is much less developed than in rats (Poole and Fish 1975; Pellis and Pasztor 1999), mice are not the preferred rodent species to study age-specific patterns of social behaviour during development. As social play behaviour in rats has been well described (Bolles and Woods 1964; Baenninger 1967; Poole and Fish 1975; Meaney and Stewart 1981; Pellis and Pellis 1987; Pellis 1988; Vanderschuren et al. 1997), we measured social play in the recently generated SERT knockout rat (Smits et al. 2006), which displays a ninefold increase in extra-neuronal 5-HT levels (Homberg et al. 2007). In line with the findings that increases in 5-HT levels reduce aggressive and sexual behaviour, we have observed that both aggressive and sexual behaviour (Homberg et al., unpublished observations) are reduced in the SERT knockout rat. The constitutive absence of the SERT in mice causes changes in the functioning of 5-HT receptors (Fabre et al. 2000; Bouali et al. 2003), so that changes in behaviour may be the result of adaptations that have occurred during development. Therefore, we also investigated social play behaviour in wild-type rats after acute treatment with compounds that increase central 5-HT levels, i.e. the SERT-blocker fluox- 
etine and 3,4-methylenedioxymethamphetamine (MDMA or "ecstasy"), which causes 5-HT release by reversing 5-HT transport.

\section{Materials and methods}

\section{Subjects}

All experiments were conducted with the approval of the animal ethics committees of the VU Medical Center, Amsterdam, The Netherlands, and the University Medical Center Utrecht, The Netherlands.

Both commercially supplied and SERT knockout rats were used in this study. Male Wistar rats (Harlan, Horst, the Netherlands) arrived at the age of 3 weeks in the animal facility. SERT knockout rats, which have been generated by ethylnitrosourea-induced mutagenesis in a Wistar background (for detailed description, see Smits et al. 2006), were bred by crosses between outcrossed (six generations) $\mathrm{SERT}^{+/-}$rats. At the age of 2 weeks, ear cuts were taken under anaesthesia and used for genotyping. At the age of 3 weeks, male $\mathrm{SERT}^{-/}$and $\mathrm{SERT}^{+/+}$rats (littermates served as controls) were transported from the breeding room to the experimental room. The animals were socially housed (four rats per type IV macrolon cage) under a normal day/light cycle (lights off at 7 P.M.) at controlled room temperature $\left(21 \pm 2^{\circ} \mathrm{C}\right)$ and relative humidity of $60 \pm$ $15 \%$. Food and water were available ad libitum. Three days after arrival, the rats were weighed and handled daily until testing.

\section{Behavioural procedure}

Testing was performed as described previously (Vanderschuren et al. 1995b). Rats, aged 28-35 days, were tested in an acrylic plastic cage $(40 \times 40 \times 60 \mathrm{~cm}[1 \times \mathrm{w} \times \mathrm{h}])$ with approximately $2 \mathrm{~cm}$ of wood shavings covering the floor. The test cage was illuminated by a $25-\mathrm{W}$ red light bulb mounted $60 \mathrm{~cm}$ above the test cage. Background noise, produced by a radio, was used to minimize the influence of extraneous sounds.

Two days preceding the test, the animals were habituated to the test cage during $10 \mathrm{~min}$. The animals of a test pair did not differ more than $10 \mathrm{~g}$ in body weight and had no previous common social experience. On the test day, test pairs were isolated for $3.5 \mathrm{~h}$ before the test to induce a halfmaximal increase in the amount of social play behaviour (Niesink and Van Ree 1989). Thirty minutes before the test, pairs of animals in group 1 were treated with 0 or $1 \mathrm{mg} / \mathrm{kg}$ fluoxetine (subcutaneous [s.c.]), animals in group 2 were pre-treated with 0 or $10 \mathrm{mg} / \mathrm{kg}$ fluoxetine and group 3 received $0,0.5,2$ or $5 \mathrm{mg} / \mathrm{kg}$ MDMA (s.c.). Pairs of similarly treated rats were tested for $15 \mathrm{~min}$ in the test cage and the test order was randomized across treatments. Behaviour of the animals was recorded on video tape, and analysis from the video tape recordings was performed afterwards. Coding of the drug solutions ensured that both during experimentation and analysis, the experimenter was unaware of the treatment of the animals. Using Observer 4.0 (Noldus Information Technology B.V., Wageningen, The Netherlands), frequencies and durations of the following behaviours was scored-pinning: one of the animals lying with its dorsal surface on the floor of the test cage with the other animal standing over it; pouncing: play soliciting by nosing the partner's nape; boxing/wrestling: facing each other in vertical position and struggling using the forepaws; following/chasing: moving in the direction of or pursuing the test partner, who moves away; social grooming and social exploration: sniffing or licking any body part of the test partner. Behaviour was assessed per pair of animals. Animals were used only once.

\section{Drugs}

Fluoxetine was purchased from Sigma-Aldrich (Schnelldorf, Germany), and MDMA was purchased from O.P.G. (Utrecht, The Netherlands). Both drugs were freshly dissolved in saline on the day of the experiment and injected s.c. in the flank in a volume of $2 \mathrm{ml} / \mathrm{kg}$.
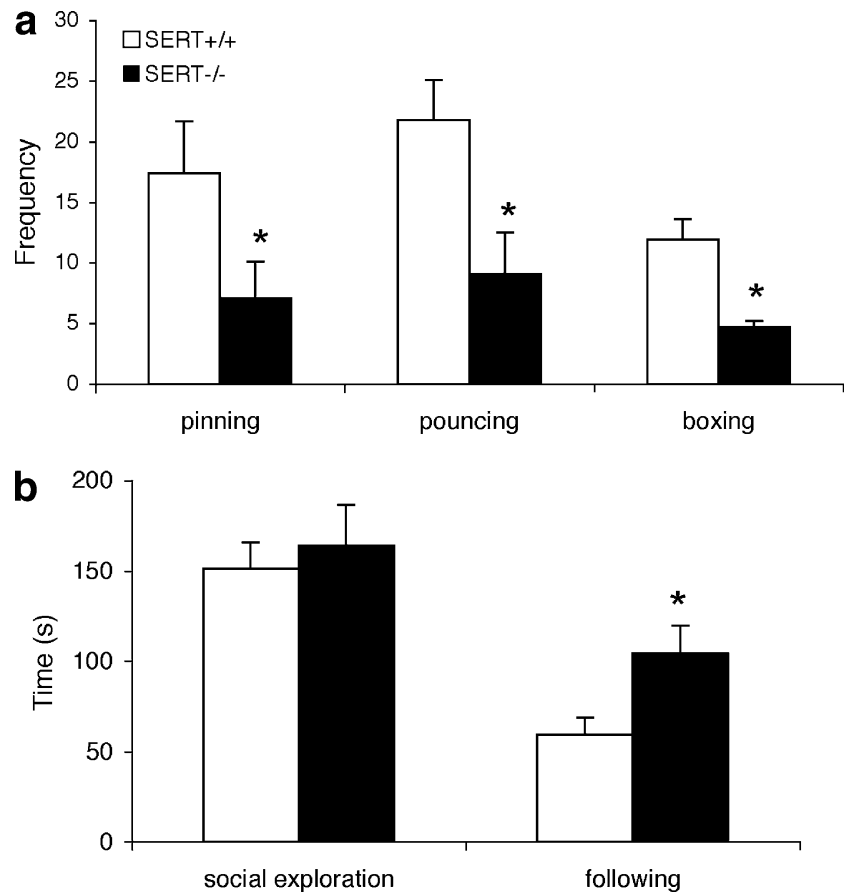

Fig. 1 Social play behaviour in peri-adolescent male SERT ${ }^{-/}$and $\mathrm{SERT}^{+/+}$rats. The data represent mean $\pm \mathrm{SEM}$ of the number of pins, pounces and boxing/wresting episodes (a) and mean \pm SEM of the duration of social exploration and following/chasing (b) during a 15 min test. Asterisk, $p<0.05$ SERT $^{-/-}$vs SERT $^{+/+}$ 
Statistical analyses

Data were analysed using one-way analysis of variance (ANOVA), followed by Student-Newman-Keuls post-hoc tests where appropriate. The level of probability for statistically significant effects was set at $p<0.05$ (n.s. $=$ non-significant).

\section{Results}

$\mathrm{SERT}^{-/-}$pairs of rats, as compared to $\mathrm{SERT}^{+/+}$pairs, showed a strong reduction in pinning frequency (Fig. 1a; $\left.F_{(2,13)}=5.78, p<0.05\right)$, pouncing frequency $\left(F_{(2,13)}=7.08\right.$, $p<0.05)$ and boxing/wresting frequency $\left(F_{(2,11)}=9.91, p<\right.$ $0.01)$. The duration of following/chasing was significantly increased in $\mathrm{SERT}^{-/-}$rats (Fig. $1 \mathrm{~b} ; F_{(2,13)}=6.5, p<0.05$ ), while social grooming and social exploration were not affected by deletion of the SERT gene (social exploration: $F_{(2,12)}=0.22$, n.s.; social grooming: $F_{(2,12)}=0.76$, n.s. $)$.

As illustrated in Fig. 2a, $1 \mathrm{mg} / \mathrm{kg}$ fluoxetine did not affect pinning $\left(F_{(2,13)}=1.33\right.$, n.s. $)$, pouncing $\left(F_{(2,13)}=2.56\right.$, n.s. $)$ and boxing/wrestling $\left(F_{(2,13)}=1.75\right.$, n.s. $)$. One-way ANOVA did not also reveal effects of $1 \mathrm{mg} / \mathrm{kg}$ fluoxetine on social exploration $\left(F_{(2,13)}=0.55\right.$, n.s. $)$, following/ chasing $\left(F_{(2,13)}=0.69\right.$, n.s. $)$ or social grooming $\left(F_{(2,13)}=\right.$ 0.00 , n.s.; Fig. 2b). A higher dose of fluoxetine, $10 \mathrm{mg} / \mathrm{kg}$, on the other hand, significantly reduced pinning $\left(F_{(2,14)}=\right.$ $15.86, p<0.005)$, pouncing $\left(F_{(2,14)}=36.18, p<0.0001\right)$, boxing/wrestling $\left(F_{(2,14)}=23.82, p<0.0005\right.$; Fig. $\left.2 \mathrm{c}\right)$ and following/chasing $\left(F_{(2,14)}=20.17, p<0.001\right)$ but not social exploration $\left(F_{(2,14)}=3.03\right.$, n.s. $)$ and social grooming $\left(F_{(2,14)}=\right.$ 0.03 , n.s.; Fig. 2d).

MDMA was tested in three different doses: $0.5,2.0$ and $5.0 \mathrm{mg} / \mathrm{kg}$. One-way ANOVA indicated that MDMA treatment dose-dependently suppressed pinning (Fig. 3a; $F_{(2,30)}=28.8, p<0.0001$, post-hoc testing: all MDMA groups vs saline $p<0.05)$, pouncing $\left(F_{(2,29)}=31.77, p<\right.$ 0.0001 , post-hoc testing: all MDMA groups vs saline $p<$ $0.05)$ and boxing $\left(F_{(2,29)}=22.07, p<0.0001\right.$, post-hoc testing: all MDMA groups vs saline $p<0.05)$. In addition, MDMA decreased following/chasing (Fig. 3b; $F_{(2,29)}=$ 8.81, $p<0.0005$, post-hoc testing: all MDMA groups vs saline $p<0.05)$. Social exploration $\left(F_{(2,30)}=6.41, p<0.005\right.$, post-hoc testing: 2 and $5 \mathrm{mg} / \mathrm{kg}$ MDMA vs saline $p<0.05$ ) and social grooming $\left(F_{(2,28)}=24.89, p<0.0001\right.$, post-hoc testing: 2 and $5 \mathrm{mg} / \mathrm{kg}$ MDMA groups vs saline $p<0.05$; Fig. 3b) were also attenuated by MDMA treatment.
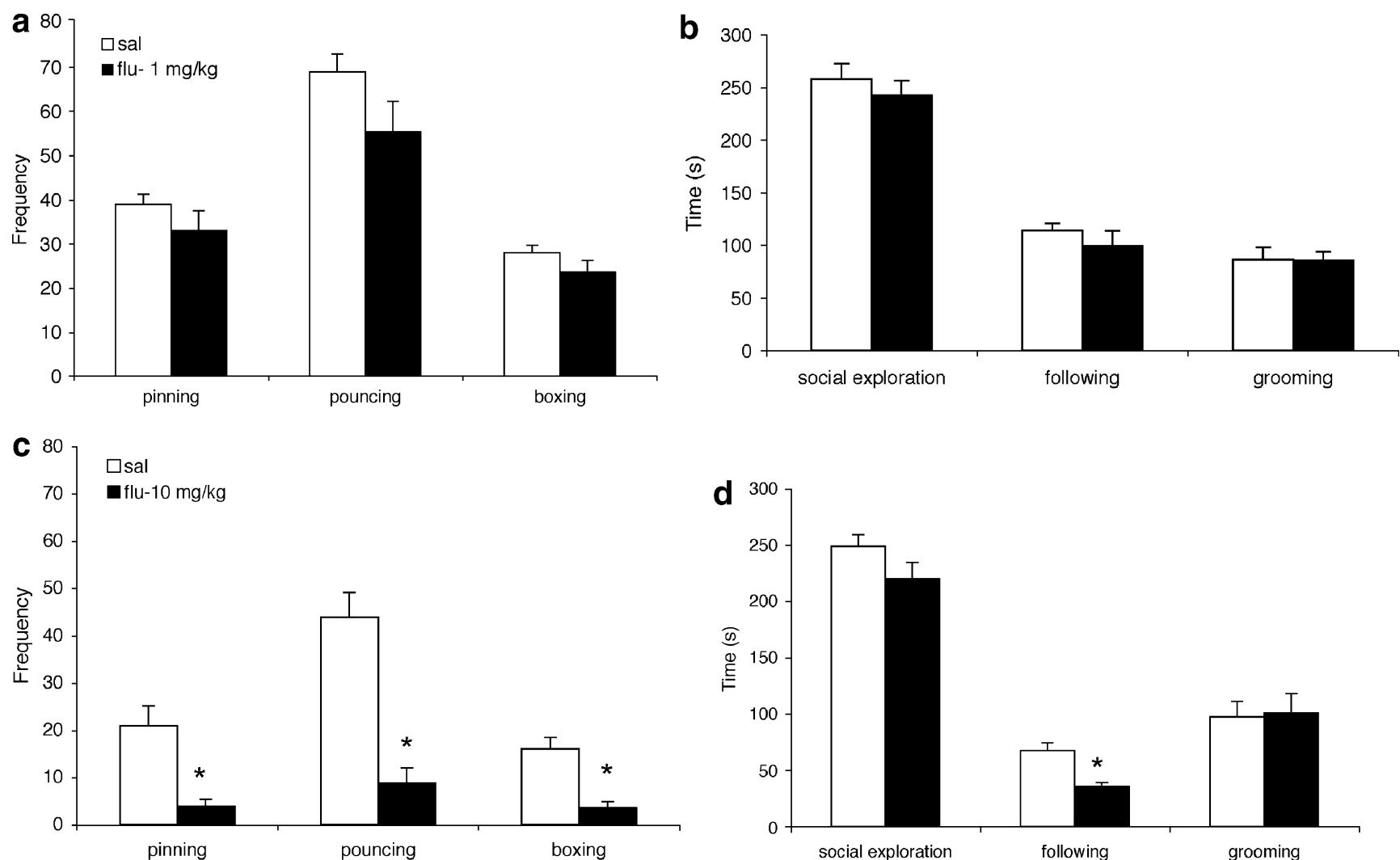

Fig. 2 Effect of fluoxetine on social play behaviour in peri-adolescent male wild-type rats. Thirty minutes before the 15 -min test, the animals were treated with $1(\mathbf{a}, \mathbf{b})$ or $10 \mathrm{mg} / \mathrm{kg}(\mathbf{c}, \mathbf{d})$ fluoxetine (s.c.). The data represent mean $\pm \mathrm{SEM}$ of the number of pins, pounces and boxing/

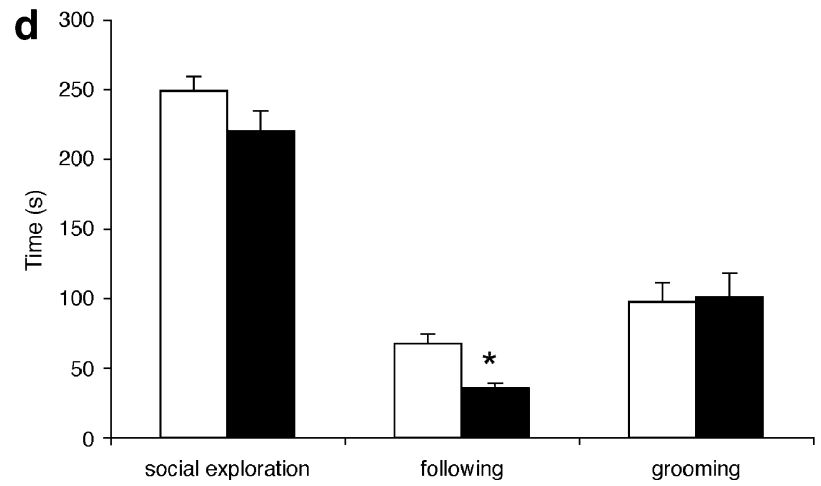

wresting episodes $(\mathbf{a}, \mathbf{c})$ and mean $\pm \mathrm{SEM}$ of the duration of social exploration, following/chasing and social grooming (b, d). Asterisk, $p<0.05$ vs saline 

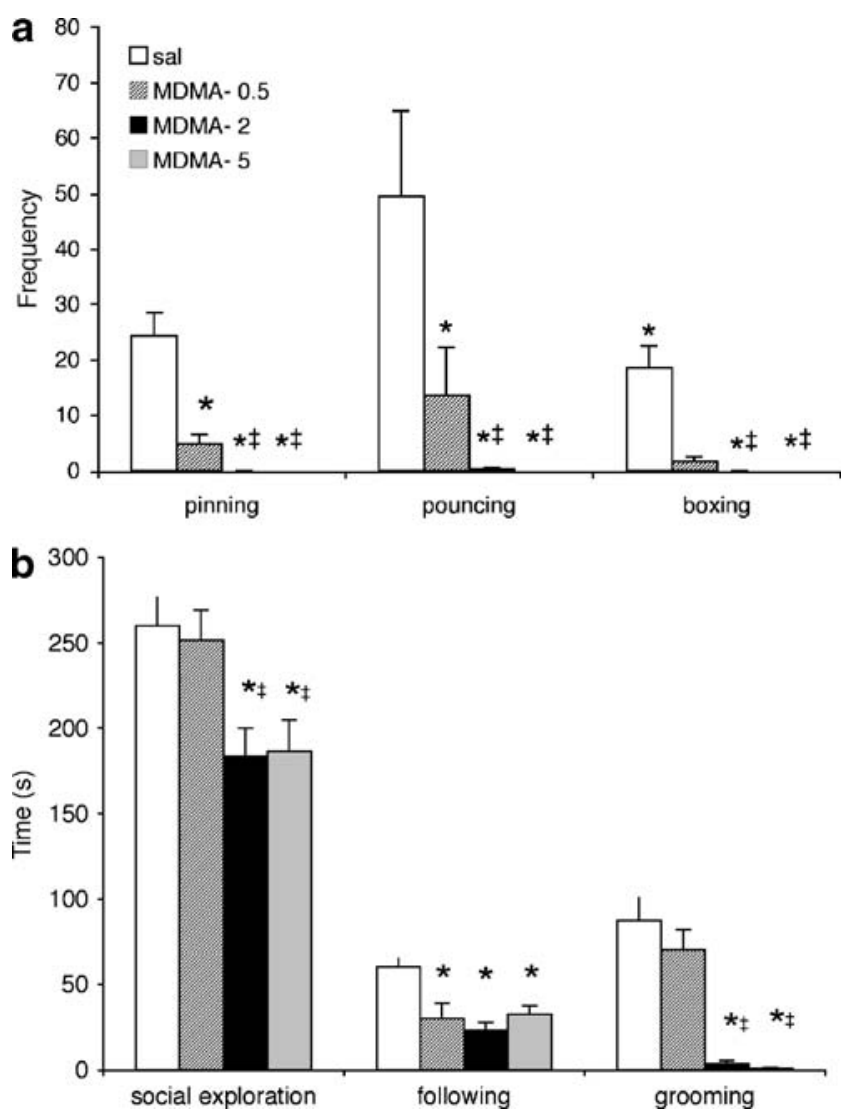

Fig. 3 Effect of MDMA on social play behaviour in peri-adolescent male wild-type rats. Thirty minutes before the 15 -min test, the animals were treated with $0,0.5,2$ or $5 \mathrm{mg} / \mathrm{kg}$ MDMA (s.c.). The data represent mean $\pm \mathrm{SEM}$ of the number of pins, pounces and boxing/ wresting episodes (a) and mean \pm SEM of the duration of social exploration, following/chasing and social grooming (b). Asterisk, $p<$ 0.05 vs saline; double cross, $p<0.05$ vs $0.5 \mathrm{mg} / \mathrm{kg}$ MDMA

\section{Discussion}

In this study, we show that increasing extra-neuronal 5-HT levels, either constitutively by deletion of the SERT gene or transiently by pharmacological manipulation (i.e. treatment with fluoxetine or MDMA), decreases social play behaviour in peri-adolescent rats. These effects were specific for playful social behaviours, i.e. pinning, pouncing and boxing/wrestling. Mixed effects were observed for following/chasing, social grooming and social exploration. The similarities between the genetic and pharmacological manipulations of the serotonergic system suggest that reduced social play behaviour in $\mathrm{SERT}^{-/}$rats is the result of increased extracellular 5-HT levels (Homberg et al. 2007).

Fluoxetine and MDMA are well known to increase central 5-HT levels, but they affect dopaminergic neurotransmission as well, raising the possibility that reduced social play is due to an effect on the dopaminergic system. Fluoxetine, at $10 \mathrm{mg} / \mathrm{kg}$ as used in the present study, increases dopamine release in the frontal cortex (Tanda et al. 1994). MDMA is a potent releaser of 5-HT, but it releases dopamine as well, albeit at higher concentrations (for reviews, see White et al. 1996; Green et al. 2003). Although psychostimulant drugs that increase central dopaminergic neurotransmission have been found to suppress social play behaviour (e.g. Beatty et al. 1982; for review, see Vanderschuren et al. 1997), these effects are most likely mediated through non-dopaminergic mechanisms because the selective dopamine reuptake inhibitor GBR-12909 and the dopamine receptor agonist apomorphine did not suppress play (Vanderschuren et al. 2005). Moreover, the pre-synaptic functioning of dopaminergic, as well as noradrenergic neurons, was not altered in SERT ${ }^{-/}$ rats (Homberg et al. 2007). Therefore, the present findings are most likely the result of altered function of the serotonergic system, rather than the dopaminergic system.

Indirect 5-HT agonists such as MDMA and parachloroamphetamine enhance locomotor activity (Geyer 1996), but the doses required to enhance locomotor activity in peri-adolescent rats are higher than those that suppress play in the present study (see Åberg et al. 2007). Fluoxetine does not alter locomotor activity (Homberg et al. 2004), and locomotor activity does not differ between $\mathrm{SERT}^{+/+}$and $\mathrm{SERT}^{-/-}$rats under both a novel and habituated conditions (Homberg et al., unpublished observations). In the present study, following/chasing, the social parameter most closely related to locomotor activity, was increased in $\mathrm{SERT}^{-/}$rats and decreased by fluoxetine and MDMA. Thus, there is no parallel in the effects of fluoxetine, MDMA and SERT knockout on locomotor activity and following/chasing. This indicates that the reduction in social play found in $\mathrm{SERT}^{-/}$ rats and after treatment with fluoxetine and MDMA is not likely to be secondary to effects on locomotor activity.

An alternative explanation of the present findings is that the decrease in social play behaviour is due to increased anxiety. Although the animals were habituated to the test cage and tested under red light conditions, reluctance to contact an unfamiliar conspecific may have interfered with our findings. SERT ${ }^{-/-}$mice display anxiety-related symptoms and reduced social interaction (Holmes et al. 2002b; Kalueff et al. 2007), MDMA and fluoxetine have anxiogenic effects in a variety of tests (Lin et al. 1999; Morley and McGregor 2000; Drapier et al. 2007) and the SSRI citalopram reduces social interaction (Dekeyne et al. 2000). MDMA has also been reported to decrease social investigation and aggression and to increase non-social exploration, which was interpreted as attempts to escape from the test arena, i.e. an anxiogenic-like effect of MDMA (Maldonado and Navarro 2001). On the other hand, prosocial effects of MDMA have also been reported (Morley and McGregor 2000). $\mathrm{SERT}^{-/-}$rats spent more time on following and chasing than $\mathrm{SERT}^{+/+}$rats. This suggests that while social play was reduced, $\mathrm{SERT}^{-/}$rats were still interested in their playing partner, which argues against 
social anxiety as an explanation of reduced play behaviour in $\mathrm{SERT}^{--}$rats. Moreover, social exploratory behaviour, which is the parameter used in the social interaction test of anxiety (File and Seth 2003), was not affected in SERT ${ }^{-/-}$ and in fluoxetine-treated rats, whereas MDMA only mildly reduced social exploration at doses that completely eliminated social play. Thus, the observed effects were relatively selective for social play, and increases in extra-neuronal 5HT levels do not induce a generalized aversion to contact an unfamiliar rat.

Long-term SSRI treatment is associated with increased extra-neuronal 5-HT levels and several compensatory adaptations (Dawson et al. 2002) that are strikingly similar to those seen in $\mathrm{SERT}^{-/-}$rats, like desensitization of preand post-synaptic 5- $\mathrm{HT}_{1 \mathrm{~A}}$ receptors (Homberg et al., unpublished observations). Chronic SSRI treatment decreases aggressive (Fuller 1997) and sexual behaviour (Olivier et al. 2006) in rats, phenotypes we also observed in $\mathrm{SERT}^{-/-}$rats (Homberg et al., unpublished observations). Because acute fluoxetine and MDMA treatment cause an immediate increase in extra-neuronal 5-HT levels without compensatory adaptations, it is likely that reduced social play in $\mathrm{SERT}^{-/-}$rats is due to the increased extra-neuronal 5-HT levels, rather than compensatory adaptations. Ansorge et al. (2004) showed that early chronic SSRI treatment in wild-type mice induces anxiety- and depressionlike phenotypes that resembles those of $\mathrm{SERT}^{-/}$mice. It may follow that $\mathrm{SERT}^{-/}$rats behave as being chronically treated with SSRIs, but given that acute and chronic SSRI treatment induce opposite effects (Silva and Brandao 2000) and that the effects of anti-depressants on the immature developing brain may differ as opposed to the effects on the mature brain of adults (Ansorge et al. 2004; Taravosh-Lahn et al. 2006), further research is required to support this suggestion. Anti-depressants are frequently prescribed to children with major depressive disorder and anxiety (Cheung et al. 2006), while there is only sparse knowledge of the effects of SSRIs on the developing brain (Spear and Brake 1983; Ansorge et al. 2004). Because social behaviour is reduced in peri-adolescent and adult $\mathrm{SERT}^{-/}$rats, it is likely that changes in 5-HT homeostasis found at adulthood in $\mathrm{SERT}^{-/-}$rats (Homberg et al. 2007) reflect the situation in the peri-adolescent $\mathrm{SERT}^{-/-}$brain. We thus propose that insight into the function of the serotonergic system in the $\mathrm{SERT}^{-/-}$(peri-adolescent) brain may be helpful to gain insight into the effects of SSRIs on the developing brain.

5-HT is considered to be an important marker of personality traits such as harm avoidance (Gerra et al. 2000), social dominance (Edwards and Kravitz 1997; Larson and Summers 2001), social attachment (Beech and Mitchell 2005) and social impulsivity (Fairbanks et al. 2001), which are relatively stable within individuals. These traits may be the result of changes in SERT function because a polymorphism in the SERT gene of humans and non-human primates, which decreases SERT expression and function (Lesch et al. 1996), has quite consistently been associated with childhood (Beitchman et al. 2006; Haberstick et al. 2006) and adult aggression (Sakai et al. 2006) and childhood (Nobile et al. 2004) and adult depression (Caspi et al. 2003). Furthermore, this polymorphism has been associated with reduced free play behaviour in monkeys (Bethea et al. 2004). Anti-social behaviour in children has been suggested to be related to developmental abnormalities in the serotonergic system, and altered social behaviour during childhood likely extends into adulthood (Van Goozen and Fairchild 2006). Thus, the observations that $\mathrm{SERT}^{--}$rats display reduced social play behaviour, reduced aggression and reduced sexual behaviour is likely to be the result of constitutive disruptions in 5-HT function. On the other hand, because social play sub-serves the development of an adequate social repertoire (Vanderschuren et al. 1997; Hol et al. 1999; Van den Berg et al. 1999), the reduction in social play in $\mathrm{SERT}^{-/-}$rats could also itself cause changes in adult social behaviour, independent of 5-HT function. Whichever possibility holds true, we think that because of their lifelong altered 5-HT homeostasis, the SERT knockout rat model may contribute to our understanding of the role of 5-HT during the development of social behaviour.

\section{References}

Åberg M, Wade D, Wall E, Izenwasser S (2007) Effect of MDMA (ecstasy) on activity and cocaine conditioned place preference in adult and adolescent rats. Neurotoxicol Teratol 29:37-46

Ansorge MS, Zhou M, Lira A, Hen R, Gingrich JA (2004) Early-life blockade of the 5-HT transporter alters emotional behaviour in adult mice. Science 306:879-881

Baenninger LP (1967) Comparison of behavioural development in socially isolated and grouped rats. Anim Behav 15:312-323

Beatty WW, Dodge AM, Dodge LJ, White K, Panksepp J (1982) Psychomotor stimulants, social deprivation and play in juvenile rats. Pharmacol Biochem Behav 16:417-422

Beech AR, Mitchell IJ (2005) A neurobiological perspective on attachment problems in sexual offenders and the role of selective serotonin re-uptake inhibitors in the treatment of such problems. Clin Psychol Rev 25:153-182

Beitchman JH, Baldassarra L, Mik H, De Luca V, King N, Bender D, Ehtesham S, Kennedy JL (2006) Am J Psychiatry 163:11031105

Bengel D, Murphy DL, Andrews AM, Wichems CH, Feltner D, Heils A, Mössner R, Westphal H, Lesch KP (1998) Altered brain serotonin homeostasis and locomotor insensitivity to 3,4-methylenedioxymethamphetamine ("Ecstasy") in serotonin transporterdeficient mice. Mol Pharmacol 53:649-655

Bethea CL, Streicher JM, Coleman K, Pau FK, Moessner R, Cameron JL (2004) Anxious behaviour and fenfluramine-induced prolactin secretion in young rhesus macaques with different alleles of the serotonin reuptake transporter polymorphism (5HTTLPR). Behav Genet 34:295-307 
Bianchi M, Fone KF, Azmi N, Heidbreder CA, Hagan JJ, Marsden CA (2006) Isolation rearing induces recognition memory deficits accompanied by cytoskeletal alterations in rat hippocampus. Eur J Neurosci 24:2894-2902

Bolles RC, Woods PJ (1964) The ontogeny of behavior in the albino rat. Anim Behav 12:427-441

Bouali S, Evrard A, Chastanet M, lesch KP, Hamon M, Adrien J (2003) Sex hormone-dependent desensitization of 5-HT1A autoreceptors in knockout mice deficient in the 5-HT transporter. Eur J Neurosci 18:2203-2212

Caspi A, Sugden K, Moffit TE, Taylor A, Craig IW, Harrington H, McClay J, Mill J, Martin J, Braithwaite A, Poulton R (2003) Influence of life stress on depression: moderation by a polymorphism in the 5-HTT gene. Science 301:386-389

Cheung AH, Emslie GJ, Mayes TL (2006) The use of antidepressants to treat depression in children and adolescents. CMAJ 174:193200

Dalley JW, Theobald DE, Pereira EA, Li PM, Robbins TW (2002) Specific abnormalities in serotonin release in the prefrontal cortex of isolation-reared rats measured during behavioural performance of a task assessing visuospatial attention and impulsivity. Psychopharmacology 164:329-340

Dawson LA, Nguyen HQ, Smith DL, Schechter LE (2002) Effect of chronic fluoxetine and WAY-100635 treatment on serotonergic neurotransmission in the frontal cortex. J Psychopharmacol $16: 145-152$

Dekeyne A, Denorme B, Monneyron S, Millan MJ (2000) Citalopram reduces social interaction in rats by activation of serotonin $(5-\mathrm{HT})_{2 \mathrm{C}}$ receptors. Neuropharmacology 39:1114-1117

Drapier D, Bentue-Ferrer D, Laviolle B, Millet B, Allain H, Bourin M, Reymann JM (2007) Effects of acute fluoxetine, paroxetine and desipramine on rats tested on the elevated plus-maze. Behav Brain Res 176:202-209

Edwards DH, Kravitz EA (1997) Serotonin, social status and aggression. Curr Opin Neurobiol 7:812-819

Fabre V, Beaufour C, Evrard A, Rioux A, Hanoun N, Lesch KP, Murphy DL, Lanfumey L, Hamon M, Martres MP (2000) Altered expression and functions of serotonin 5-HT1A and 5HT1B receptors in knock-out mice lacking the 5-HT transporter. Eur J Neurosci 12:2299-2310

Fairbanks LA, Melega WP, Jorgensen MJ, Kaplan JR, McGuire MT (2001) Social impulsivity inversely associated with CSF 5-HIAA and fluoxetine exposure in vervet monkeys. Neuropsychopharmacology 24:370-378

Ferdman N, Murmu RP, Bock J, Braun K, Leshem M (2007) Weaning age, social isolation, and gender, interact to determine adult explorative and social behavior, and dendritic and spine morphology in prefrontal cortex of rats. Behav Brain Res 180:174-182

Ferrari PF, Palanza P, Parmigiani S, de Almeida RM, Miczek KA (2005) Serotonin and aggressive behaviour in rodents and nonhuman primates: predispositions and plasticity. Eur J Pharmacol 526:259-273

File SE, Seth P (2003) A review of 25 years of the social interaction test. Eur J Pharmacol 463:35-53

Fuller RW (1997) The influence of fluoxetine on aggressive behaviour. Neuropsychopharmacology 16:373-374

Gerra G, Zaimovic A, Timpano M, Zambelli U, Delsignore R, Brambilla F (2000) Neuroendocrine correlates of temperamental traits in humans. Psychoneuroendorinology 25:479-496

Geyer MA (1996) Serotonergic functions in arousal and motor activity. Behav Brain Res 73:31-35

Green AR, Mechan AO, Elliott JM, O'Shea E, Colado MI (2003) The pharmacology and clinical pharmacology of 3,4-methylenedioxymethamphetamine (MDMA, "ecstasy"). Pharmacol Rev $55: 463-508$
Haberstick BC, Smolen A, Hewitt JK (2006) Family-based association test of the 5HTTLPR and aggressive behaviour in a general population sample of children. Biol Psychiatry 59:36-43

Howes SR, Dalley JW, Morrison CH, Robbins TW, Everitt BJ (2000) Leftward shift in the acquisition of cocaine self-administration in isolation-reared rats: relationship to extracellular levels of dopamine, serotonin and glutamate in the nucleus accumbens and amygdala-striatal FOS expression. Psychopharmacology 151:55-63

Heidbreder CA, Weiss IC, Domeney AM, Pryce C, Homberg J, Hedou G, Feldon J, Moran MC, Nelson P (2000) Behavioral, neurochemical and endocrinological characterization of the early social isolation syndrome. Neuroscience 100:749-768

Higley JD, Linnoila M (1997) Low central nervous system serotonergic activity is traitlike and correlates with impulsive behaviour. A nonhuman primate model investigating genetic and environmental influences on neurotransmission. Ann NY Acad Sci 836:39-56

Hol T, Van den Berg C, Van Ree JM, Spruijt BM (1999) Isolation during the play period in infancy decreases adult social interactions in rats. Behav Brain Res 100:91-97

Holmes A, Murphy DL, Crawley JN (2002a) Reduced aggression in mice lacking the serotonin transporter. Psychopharmacology 161:160-167

Holmes A, Yang JL, Murphy DL, Crawley JN (2002b) Evaluation of antidepressant-related behavioural responses in mice lacking the serotonin transporter. Neuropsychopharmacology 27:914-923

Homberg JR, Arends B, Wardeh G, Raaso HS, Schoffelmeer AN, de Vries TJ (2004) Individual differences in the effects of serotonergic anxiolytic drugs on the motivation to self-administer cocaine. Neuroscience 128:121-130

Homberg JR, Olivier JDA, Smits BMG, Mul JD, Mudde J, Verheul M, Nieuwenhuizen OFM, Ronken E, Cremers T, Schoffelmeer ANM, Ellenbroek BA, Cuppen E (2007) Characterization of the serotonin transporter knockout rat: A selective change in the functioning of the serotonergic system. Neuroscience 146:16621676

Kalueff AV, Fox MA, Gallagher PS, Murphy DL (2007) Hypolocomotion, anxiety and serotonin syndrome-like behavior contribute to the complex phenotype of serotonin transporter knockout mice. Genes Brain Behavior 6:389-400

Knutson B, Panksepp J, Pruitt D (1996) Effects of fluoxetine on play dominance in juvenile rats. Aggress Behav 22:297-307

Larson ET, Summers CH (2001) Serotonin reverses dominant social status. Behav Brain Res 121:95-102

Lesch KP, Bengel D, Heils A, Sabol SZ, Greenberg BD, Petri S, Benjamin J, Muller CR, Hamer DH, Murphy DL (1996) Association of anxiety-related traits with a polymorphism in the serotonin transporter gene regulatory region. Science 274:15271531

Lin HQ, Burden PM, Chriestie MJ, Johnston GAR (1999) The anxiogenic-like anxiolytic-like effects of MDMA on mice in the elevated plus maze: a comparison with amphetamine. Pharmacol Biochem Behav 62:403-408

Maestripieri D, McCormack K, Lindell SG, Higley JD, Sanchez MM (2006) Influence of parental style on the offspring's behaviour and CSF monoamine metabolite levels in crossfostered and noncrossfostered female rhesus monkeys. Behav Brain Res 25 (175):90-95

Maldonado E, Navarro F (2001) MDMA ('ecstacy') exhibits and anxiogenic-like activity in social encounters between male mice. Pharmacol Res 44:27-31

Meaney MJ, Stewart J (1981) A descriptive study of social development in the rat (Rattus norvegicus). Anim Behav 29:34-45

Morley KC, McGregor IS (2000) ( \pm )-3,4-Methylenedioxymethamphetamine (MDMA, 'Ecstasy') increases social interaction in rats. Eur J Pharmacol 408:41-49 
New AS, Buchsbaum MS, Hazlett EA, Goodman M, Koeningsberg HW, Lo J, Iskander L, Newmark R, Brand J, O'Flynn K, Siever LJ (2004) Fluoxetine increases relative metabolic rate in prefrontal cortex in impulsive aggression. Psychopharmacology 176:451-458

Niesink RJM, Van Ree (1989) Involvement of opioid and dopaminergic systems in isolation-induced pinning and social grooming of young rats. Neuropharmacology 28:411-418

Nobile M, Cataldo MG, Giorda R, Battaglia M, Baschirotto C, Bellina M, Marino C, Molteni M (2004) A case-control and family-based association study of the 5-HTTLPR in pediatric-onset depressive disorders. Biol Psychiatry 56:292-295

Normansell L, Panksepp J (1985) Effects of quipazine and methysergide on play in juvenile rats. Pharmacol Biochem Behav 22:885887

Olivier B, Chan JS, Pattij T, de Jong TR, Oosting RS, Veening JG, Waldinger MD (2006) Psychopharmacology of male rat sexual behaviour: modeling human sexual dysfunctions. Int J Impot Res 18(Suppl 1):S14-S23

Panksepp J, Normansell L, Cox JF, Crepeau LJ, Sacks DS (1987) Psychopharmacology of social play. In: Olivier B, Mos J, Brain PF (eds) Ethopharmacology of agonistic behaviour in animals and humans. Martinus Nijhoff, Dordrecht, pp 132-144

Pellis SM (1988) Agonistic versus amicable targets of attack and defense: consequences for the origin, function and descriptive classification of play-fighting. Aggress Behav 14:85-104

Pellis SM, Pasztor TJ (1999) The developmental onset of a rudimentary form of play fighting in C57 mice. Dev Psychobiol 34:175-182

Pellis SM, Pellis VC (1987) Play-fighting differs from serious fighting in both target of attack and tactics of fighting in the laboratory rat Rattus norvegicus. Aggress Behav 13:227-242

Poole TB, Fish J (1975) An investigation of playful behavior in Rattus norvegicus and Mus musculus (Mammalia). J Zool 175:61-71

Popova LK (2006) From genes to aggressive behaviour: the role of serotonergic system. Bioessays 28:495-503

Sakai JT, Young SE, Stallings MC, Timberlake D, Smolen A, Stetler GL, Crowley TJ (2006) Case-control and within-family tests for an association between conduct disorder and 5HTTLPR. Am J Med Genet B Neuropsychiatr Genet 141:825-832

Serretti A, Mandelli L, Lorenzi C, Landoni S, Calati R, Insacco C, Cloninger CR (2006) Temperament and character in mood disorders: influence of DRD4, SERTPR, TPH and MAO-A polymorphisms. Neuropsychobiology 53:9-16
Silva RC, Brandao ML (2000) Acute and chronic effects of gepirone and fluoxetine in rats tested in the elevated plus-maze: an ethological analysis. Pharmacol Biochem Behav 65:209-216

Siviy SM (1998) Neurobiological substrates of play behavior: glimpses into the structure and function of mammalian playfulness. In: Bekoff M, Byers JA (eds) Animal play. Cambridge University Press, Cambridge, pp 221-242

Smits BM, Mudde JB, Van de Belt J, Verheul M, Olivier J, Homberg J, Guryev V, Cools AR, Ellenbroek BA, Plasterk RH, Cuppen E (2006) Generation of gene knockouts and mutant models in the laboratory rat by ENU-driven target-selected mutagenesis. Pharmacogenet Genomics 16:159-169

Spear LP, Brake SC (1983) Periadolescence: age-dependent behaviour and psychopharmacological responsivity in rats. Dev Psychobiol 16:83-109

Tanda G, Carboni E, Frau R, Di Chiara G (1994) Increase of extracellular dopamine in the prefrontal cortex: a trait of drugs with antidepressant potential? Psychopharmacology 115:285-288

Taravosh-Lahn K, Bastida C, Delville Y (2006) Differential responsiveness to fluoxetine during puberty. Behav Neurosci 120:1084-1092

Van den Berg CL, Hol T, Van Ree JM, Spruijt BM, Everts H, Koolhaas JM (1999) Play is indispensable for an adequate development of coping with social challenges in the rat. Dev Psychobiol 34:129-138

Vanderschuren LJMJ, Spruijt BM, Hol T, Niesink RJM, Van Ree JM (1995a) Sequential analysis of social play behavior in juvenile rats: effects of morphine. Behav Brain Res 72:89-95

Vanderschuren LJMJ, Niesink RJM, Spruijt BM, Van Ree JM (1995b) Effects of morphine on different aspects of social play in juvenile rats. Psychopharmacology 117:225-31

Vanderschuren LJMJ, Niesink RJM, van Ree JM (1997) The neurobiology of social play behaviour in rats. Neurosci Biobehav Rev 21:309-326

Vanderschuren LJMJ, Roose S, Broekhoven MH, Schiepers OJG, De Vries TJ, Schoffelmeer ANM (2005) Methylphenidate-induced suppression of social play behavior: a behavioral and pharmacological analysis in rats. Behav Pharmacol 16(Suppl 1):S100

Van Goozen SH, Fairchild G (2006) Neuroendocrine and neurotransmitter correlates in children with antisocial behaviour. Horm Behav 50:647-654

White SR, Obradovic T, Imel KM, Wheaton MJ (1996) The effects of methylenedioxymethamphetamine (MDMA, "Ecstasy") on monoaminergic neurotransmission in the central nervous system. Prog Neurobiol 49:455-479 